Abstracta Iranica Iranica

Revue bibliographique pour le domaine irano-aryen

Volume 32-33 | 2013

Comptes rendus des publications de 2009-2010

\title{
Dušan Deák. Śahādat ou Śahā Datta? Locating the Mysterious Fakir in the Marathi Texts
}

\section{Nicolas Dejenne}

\section{(2) OpenEdition}

1 Journals

Édition électronique

URL : http://journals.openedition.org/abstractairanica/40618

DOI : 10.4000/abstractairanica.40618

ISSN : 1961-960X

\section{Éditeur :}

CNRS (UMR 7528 Mondes iraniens et indiens), Éditions de l'IFRI

\section{Édition imprimée}

Date de publication : 1 décembre 2013

ISSN : 0240-8910

\section{Référence électronique}

Nicolas Dejenne, « Dušan Deák. Śahādat ou Śahā Datta? Locating the Mysterious Fakir in the Marathi Texts », Abstracta Iranica [En ligne], Volume 32-33 | 2013, document 268, mis en ligne le 01 juillet 2016, consulté le 03 octobre 2020. URL : http://journals.openedition.org/abstractairanica/40618; DOI : https://doi.org/10.4000/abstractairanica.40618

Ce document a été généré automatiquement le 3 octobre 2020.

Tous droits réservés 


\title{
Dušan Deák. Śahādat ou Śahā Datta? Locating the Mysterious Fakir in the Marathi Texts
}

\author{
Nicolas Dejenne
}

\section{RÉFÉRENCE}

Dušan Deák. « Śahādat ou Śahā Datta? Locating the Mysterious Fakir in the Marathi Texts », in : D. Hermann, F. Speziale, eds., Muslim Cultures in the Indo-Iranian World during the Early-Modern and Modern Periods. Berlin, Institut Français de Recherche en Iran Klaus Schwarz Verlag, 2010, p. 501-532. (Bibliothèque iranienne, vol. 69 Islamkundliche Untersuchungen, vol. 290).

1 L'article de Dušan Deák aborde la question des modes de rencontre entre les traditions hindoues et musulmanes en Asie du sud à partir de la coloration islamique donnée à la divinité hindoue Dattātreya dans quelques textes marathis de la période moderne. Dattātreya est un personnage particulièrement difficile à caractériser de la mythologie hindoue, à la fois ou alternativement dieu, sage, incarnation divine, mais dont le prestige et l'ancienneté (dès le début de notre ère) dans les textes épiques sanskrits sont indéniables; la région où il a obtenu, et occupe encore, le plus haut statut, est l'Inde de l'ouest, notamment le Maharashtra où un culte lui est rendu par divers groupes hindous et où il est censé s'être incarné dans plusieurs personnalités historiques. Après avoir rappelé ces éléments fondamentaux sur Dattātreya de même que les caractéristiques communes aux "saints hommes" en Inde, qu'ils soient hindous ou musulmans et quelle que soit la diversité de leurs appellations, l'A. engage le lecteur dans une enquête sur les textes en langue marathi où la figure de Dattātreya apparaît en relation avec des personnages musulmans. Les plus anciens de ces textes datent du milieu du XVI ${ }^{e}$ s. et présentent Dattātreya dans un rôle de conseiller d'un roi musulman (rappelons que des sultanats, employant de nombreux hindous dans leur administration, s'établissent dans le Deccan à partir du XIV ${ }^{e}$ s.); des hagiographies 
d'Eknāth, un saint brahmane mort en 1599, rédigées au XVIII ${ }^{e}$ s. par des auteurs brahmanes, se révèlent plus problématiques en ce qu'elles présentent comme maître spirituel d'Eknāth un personnage mal identifiable mais semble-t-il musulman (le «mystérieux fakir» du titre de l'article), incarnation inattendue de Dattātreya inattendue mais pas inimaginable du fait des fortes tendances transgressives qui lui sont attribuées dans certaines sectes hindoues. Le dernier texte étudié par l'A., rédigé dans une langue mêlant marathi et hindoustani, date probablement du XIX ${ }^{\mathrm{e}}$ s. et était utilisé dans le culte de Dattātreya dans des zones limitées du Maharashtra: intitulé Śahā Datta Kalamā, ce texte semble témoigner d'un certain syncrétisme puisque les références hindoues y voisinent avec l'évocation du prophète Mahomet et l'usage d'une terminologie soufie. Le titre même de l'ouvrage résume le caractère ambigu du texte puisqu'il peut être compris soit comme «la profession de foi (kalamā) de Śahā Datta ", ie le roi Dattātreya qui joue le rôle de guide spirituel dans les temps de décadence du kaliyuga, soit comme " une parole de confession musulmane " (sens en urdu, comme en arabe, du mot šahādat). L'A. suggère que le lien entre éléments hindous et islamiques du texte, notamment dans ses passages eschatologiques, pourrait s'expliquer par une influence de la branche Nizārī de l'ismaélisme. L'A. reconnaît que de nombreuses questions restent irrésolues, dont la plus cruciale est sans doute la suivante: si ces textes témoignent certainement des efforts d'adaptation des élites brahmaniques et des sectes hindoues à un environnement socio-politique où l'influence musulmane était majeure et parfois dominante, faut-il lire dans ces textes une tentative de sanskritisation et de normalisation (aux yeux de la communauté hindoue) du personnage du fakir musulman ou, plutôt, une volonté d'islamisation d'une divinité hindoue majeure du Maharashtra? Rédigé dans un anglais parfois un peu déroutant, l'article de Deák, qui présente l'état actuel de recherches en cours, constitue en tout cas un fort utile complément à l'ouvrage de base d'Antonio Rigopoulos sur Dattātreya, Dattātreya the Immortal, Guru, Yogin and Avatāra: A study of the transformative and inclusive character of a multi-faceted Hindu deity (New York, 1998).

\section{AUTEURS}

\section{NICOLAS DEJENNE}

Université Sorbonne Nouvelle-Paris 3 / Mondes iranien et indien, Paris 